OPEN ACCESS

Edited by:

Pablo Urrutia Cordero,

Lund University, Sweden

Reviewed by:

Kelley Fritz,

Southeast Missouri State University,

United States

Lenin Dzibakwe Chari,

Rhodes University, South Africa

*Correspondence:

Cornelia W. Twining

cornelia.twining@gmail.com

Specialty section:

This article was submitted to Biogeography and Macroecology, a section of the journal

Frontiers in Ecology and Evolution

Received: 02 July 2021 Accepted: 09 August 2021

Published: 27 August 2021

Citation:

Twining CW, Parmar TP

Mathieu-Resuge M, Kainz MJ,

Shipley JR and Martin-Creuzburg D

(2021) Use of Fatty Acids From

Aquatic Prey Varies With Foraging

Strategy. Front. Ecol. Evol. 9:735350.

doi: $10.3389 /$ fevo.2021.735350

\section{Use of Fatty Acids From Aquatic Prey Varies With Foraging Strategy}

\author{
Cornelia W. Twining ${ }^{1,2,3 *}$, Tarn Preet Parmar', Margaux Mathieu-Resuge ${ }^{4}$, \\ Martin J. Kainz ${ }^{4,5}$, Jeremy Ryan Shipley ${ }^{2,3}$ and Dominik Martin-Creuzburg ${ }^{1}$

\begin{abstract}
1 Limnological Institute, University of Konstanz, Konstanz, Germany, ${ }^{2}$ Max Planck Institute of Animal Behavior, Radolfzell, Germany, ${ }^{3}$ Swiss Federal Institute of Aquatic Science and Technology, Kastanienbaum, Switzerland, ${ }^{4}$ WasserCluster Lunz-Inter-University Centre for Aquatic Ecosystem Research, Lunz am See, Austria, ${ }^{5}$ Department of Biomedical

Research, Danube University Krems, Krems an der Donau, Austria
\end{abstract}

Across ecosystems, resources vary in their nutritional composition and thus their dietary value to consumers. Animals can either access organic compounds, such as fatty acids, directly from diet or through internal biosynthesis, and the extent to which they use these two alternatives likely varies based on the availability of such compounds across the nutritional landscape. Cross-ecosystem subsidies of important dietary nutrients, like omega-3 long-chain polyunsaturated fatty acids (n-3 LC-PUFA), may provide consumers with the opportunity to relax the demands of synthesis and rely upon dietary flexibility rather than internal metabolic processes. Here, we examined how dietary flexibility and distance from a lake influenced the degree to which generalist insectivores relied upon dietary n-3 LC-PUFA from emergent aquatic insects versus n-3 LC-PUFA synthesized from precursor compounds found in terrestrial insects. We used bulk and compound-specific stable isotope analyses to understand spider and insectivorous bird (Blue Tit; Cyanistes caeruleus) reliance on aquatic and terrestrial resources, including dietary PUFA sources, along a riparian to upland gradient from a lake. We simultaneously investigated n-3 LC-PUFA synthesis ability in nestlings using ${ }^{13} \mathrm{C}$ fatty acid labeling. We found that riparian spiders took advantage of emergent aquatic insect subsidies, deriving their overall diet and their n-3 PUFA from aquatic resources whereas nestling birds at all distances and upland spiders relied upon terrestrial resources, including PUFA. Our ${ }^{13} \mathrm{C}$ labeling experiment demonstrated that nestling tits were able to synthesize the n-3 LC-PUFA docosahexaenoic acid from the dietary precursor $\alpha$-linolenic acid, suggesting that they are not limited by aquatic resources to satisfy their LC-PUFA requirements. Overall, this study suggests that habitat generalist insectivores vary in the degree to which they can shift diet to take advantage of high-quality aquatic resources depending upon both their foraging flexibility and internal synthesis capacity.

Keywords: compound-specific stable isotopes, birds, emergent aquatic insects, nutrition, PUFA, spiders

\section{INTRODUCTION}

Cross-ecosystem subsidies can provide sources of physiologically important nutrients for a diversity of consumers. Nutritional linkages between systems can range from local exchanges, like seasonal fluxes of insects between aquatic and terrestrial food webs (Nakano et al., 1999; Kawaguchi et al., 2003), to regional-scale interactions in the form of migratory fishes that swim hundreds of 
kilometers from the ocean to their freshwater spawning grounds (Durbin et al., 1979; Schindler et al., 2003; Flecker et al., 2010). Research on cross-ecosystem subsidies has generally concentrated on quantifying fluxes of energy or elemental nutrients, such as phosphorus and nitrogen (e.g., Polis et al., 1997; Marcarelli et al., 2011). However, animals also require a diversity of organic compounds, such as vitamins, amino acids, and fatty acids, that vary in availability across the landscape (e.g., Hixson et al., 2015; Twining et al., 2019, 2021).

Aquatic ecosystems appear to be uniquely important sources of omega-3 long-chain polyunsaturated fatty acids (n-3 LC-PUFA) for consumers across ecosystems. Both aquatic and terrestrial animals require n-3 LC-PUFA, in particular eicosapentaenoic acid (EPA, 20:5n-3) and docosahexaenoic acid (DHA, 22:6n-3), in order to survive and avoid growth limitation (e.g., Martin-Creuzburg et al., 2010; Brenna and Carlson, 2014). However, although both aquatic and terrestrial primary producers contain the n-3 LC-PUFA precursor $\alpha$-linolenic acid (ALA; 18:3n-3), they differ fundamentally in their n-3 LC-PUFA content. While a diversity of freshwater primary producers contain both EPA and DHA (Hixson et al., 2015; Twining et al., 2016a), few vascular terrestrial plants contain any detectable n-3 LC-PUFA (Hixson et al., 2015; Twining et al., 2016a). These ecosystem-based differences in fatty acid composition also persist at higher trophic levels: studies suggest that terrestrial insects contain little to no n-3 LC-PUFA, while emergent freshwater insects are rich in these compounds, especially EPA (Hixson et al., 2015; Martin-Creuzburg et al., 2017; Twining et al., 2019). Emergent aquatic insects from streams and lakes thus subsidize terrestrial predators not only with energy (e.g., Nakano and Murakami, 2001; Baxter et al., 2005; Kautza and Sullivan, 2016), but also with these physiologically important organic compounds (Martin-Creuzburg et al., 2017; Twining et al., 2019; Mathieu-Resuge et al., unpublished; Kowarik et al., 2021).

Within riparian zones, emergent insects from streams and lakes serve as key sources of n-3 LC-PUFA for terrestrial insectivores, such as spiders, bats, and birds (e.g., Lam et al., 2013; Fritz et al., 2017; Twining et al., 2019; Kowarik et al., 2021). A growing number of studies suggests that the higher n-3 LCPUFA content of emergent aquatic insects compared to terrestrial insects makes them particularly valuable for riparian insectivores. For example, insectivorous riparian birds as well as spiders show evidence of increased immunocompetence when they consume more n-3 LC-PUFA and aquatic resources (Twining et al., 2016b; Fritz et al., 2017). Nestling Tree Swallows (Tachycineta bicolor) and Eastern Phoebes (Sayornis phoebe) put on more mass when fed diets rich in EPA and DHA (Twining et al., 2016b, 2019). The condition and survival of riparian insectivore nestlings also increases with greater access to aquatic subsidies (Dodson et al., 2016; Twining et al., 2018b; Berzins et al., 2021).

While elemental nutrients, like phosphorus, are strictly essential for all organisms, animals can obtain certain organic nutrients directly from diet or through metabolic means (Twining et al., 2021). Some species have essential requirements for organic nutrients (e.g., DHA), while others can readily synthesize these nutrients from dietary precursors (e.g., ALA). At the same time, some animals display remarkable intraspecific dietary flexibility across populations and individuals, consuming a diversity of dietary items of variable nutritional composition (e.g., brown bears, Ursus arctos: Costello et al., 2016; Coogan et al., 2018) while other species consume highly specialized diets of relatively consistent nutritional composition (e.g., giant pandas, Ailuropoda melanoleuca, Nie et al., 2015). Animals without direct access to dietary sources of important organic nutrients, like n-3 LC-PUFA, must synthesize these compounds from dietary precursors. For example, chickens, which typically consume terrestrial insects and plants, are able to synthesize n3 LC-PUFA from ALA (Gregory and James, 2014), which is readily available from terrestrial primary producers and insects, making chickens less reliant on direct n-3 LC-PUFA subsidies. In contrast, Tree Swallows, which regularly consume n-3 LCPUFA-rich emergent aquatic insects, have limited n-3 LC-PUFA synthesis capabilities (Twining et al., 2018a). Consequently, the nutritional value of aquatic subsidies for consumers likely varies based on both consumer metabolic ability (i.e., internal synthesis capacity) and foraging flexibility (e.g., ability to capture flying emergent aquatic insects).

Recent studies have demonstrated that riparian specialists benefit from emergent aquatic insect subsidies of n-3 LC-PUFA, but it remains unclear if habitat generalists that live in both riparian and upland areas also opportunistically obtain n-3 LCPUFA from emergent aquatic insects. Even if generalists are capable of internally synthesizing n-3 LC-PUFA from ALA, they may benefit from direct dietary sources of n-3 LC-PUFA that alleviate the need to convert ALA into n-3 LC-PUFA through internal biosynthesis. Controlled diet studies suggest that n-3 LCPUFA synthesis rates can be relatively plastic based on dietary n-3 LC-PUFA and precursor availability (e.g., Jing et al., 2013; Katan et al., 2019). However, habitat generalists must also possess the foraging flexibility to take advantage of aquatic subsidies. For example, while avian aerial insectivore abundance is positively associated with emergent aquatic insects, suggesting that they regularly use such prey, species from other more specialized avian feeding guilds (e.g., bark-probers) do not show the same relationships with emergent insects (Schilke et al., 2020). This is unsurprising because aerial insectivores include a diversity of flying insects from several different aquatic orders in their diet (Twining et al., 2018b), while feeding modes like bark-probing or ground-foraging preclude the capture of flying emergent insect prey (Schilke et al., 2020). In contrast, web-building spiders and predatory beetles (e.g., Staphylinidae) that live across both upland and riparian zones opportunistically consume aquatic resources in areas where emergent insects are readily available (Kato et al., 2004; Paetzold et al., 2005; Stenroth et al., 2015; Kautza and Sullivan, 2016; Chari et al., 2020; Kowarik et al., 2021), suggesting that their foraging modes allow them to capture a wider array of different prey. Riparian spiders have also been found to have elevated n-3 LC-PUFA content relative to upland spiders (Fritz et al., 2017; Chari et al., 2020; Kowarik et al., 2021).

Here, we examined the degree to which habitat generalists employed metabolic and dietary flexibility to access n-3 LCPUFA along a riparian to inland gradient. We assessed aquatic and terrestrial arthropod prey availability and fatty acid composition and then used bulk stable isotopes to understand 
spider and insectivorous bird (Blue Tit, Cyanistes caeruleus) reliance on aquatic and terrestrial resources. We used a combination of natural abundance and ${ }^{13} \mathrm{C}$-enriched compoundspecific stable isotope approaches (Twining et al., 2020) to determine from where spiders and nestlings obtained their PUFA and how PUFA sources for insectivorous consumers varied with distance from the lake. As part of this, we dosed a subset of Blue Tit nestlings with ${ }^{13} \mathrm{C}$-enriched ALA to examine their ability to convert ALA into n-3 LC-PUFA.

We predicted that the share of aquatic resources and n-3 LCPUFA in the diets of spiders and birds would decrease with distance from the lake. Because previous studies suggest that during the breeding season, tits primarily feed their nestlings caterpillars and spiders (Royama, 1970; Naef-Daenzer et al., 2000; Isaksson et al., 2015), we expected that riparian tit nestlings would either have access to aquatic-derived n-3 LC-PUFA directly through small amounts of aquatic insects in their diet or indirectly by consuming riparian spiders that consumed aquatic insects. We expected that upland tit nestlings would only have access to n-3 LC-PUFA-poor terrestrial arthropods, requiring greater internal n-3 LC-PUFA synthesis.

\section{MATERIALS AND METHODS}

\section{Study Area and Nest Box Monitoring}

We examined spider and Blue Tit resource use and fatty acid sources (i.e., emergent freshwater insects and terrestrial insects) at varying distances from the shore of Lake Mindelsee $\left(47.75^{\circ} \mathrm{N}, 9.02^{\circ} \mathrm{E}\right)$, a midsize $\left(1.02 \mathrm{~km}^{2}\right)$ mesotrophic lake in southwestern Germany. The riparian and upland areas to the south of the lake, where we worked, are covered by mixed forests that are dominated by beech and conifers. These areas have been managed as a nature preserve for recreation and have been forested since the 1930s. We equally divided 150 wooden nest boxes $(120 \mathrm{~mm} \times 100 \mathrm{~mm} \times 250 \mathrm{~mm})$ for Blue Tits in January and February of 2019 along three walking paths at varying distances from the lake (Supplementary Figure 1): (1) nearshore boxes ( $10 \mathrm{~m}$ of the lake), (2) middle distance boxes $(\sim 500 \mathrm{~m}$ from the lake), and (3) far boxes $(\sim 1,000 \mathrm{~m}$ from the lake).

We secured wooden boxes at a height of $2 \mathrm{~m}$ with aluminum forestry nails to mature trees (primarily beech) that were $\sim 30 \mathrm{~m}$ apart. To minimize disturbance during nest checks, we placed cardboard boxes inside each nest box, which allowed us to quickly remove nests within cardboard boxes for visual inspection rather than reaching into nest boxes for inspection by hand and disturbing nest construction. Each box's GPS location was recorded using a Garmin eTrex $30 \times$. We began bi-weekly nest checks on tit boxes at the beginning of April. During each check, we noted signs of initial nest occupancy (e.g., single pieces of moss or tearing at edges of cardboard) and nest stage (i.e., initial moss collection, large amounts of moss without a cup, and large amount of moss with completed cup). Following nest completion, we monitored the presence, number, and temperature (warm or cool) of eggs in a nest approximately every other day. Once we detected warm eggs and/or no change in number of eggs, we stopped checking boxes until estimated hatch date, approximately 10 days later.

\section{Resource Availability}

We assessed resource availability throughout the tit breeding season. To assess the availability of larval Lepidopera (i.e., caterpillars), which are thought to be the primary food resources for tit nestlings, we placed a $1 \mathrm{~m}^{2}$ white beating sheet, secured with a wooden frame, under 10 haphazardly selected trees and/or bushes per distance (all located between trees with nestboxes), which we shook vigorously. Weekly from April 25, 2019 to May 26, 2019, we collected caterpillars with a beating sheet, stored them in plastic capsules on ice until freezing them at $-20^{\circ} \mathrm{C}$, and recorded the GPS location. We also collected any Arachnida (i.e., spiders) found on beating sheets and recorded their GPS location. Emergence traps with sampling areas of $0.36 \mathrm{~m}^{2}$ were deployed on Lake Mindelsee at distances of $1 \mathrm{~m}(n=3), 3 \mathrm{~m}(n=3), 7 \mathrm{~m}$ $(n=1)$, and $9 \mathrm{~m}(n=1)$ from shore. We collected emergent aquatic insects from traps every 3-6 days between March 25, 2019 and May 27, 2019. Malaise traps with sampling areas of $1.72 \mathrm{~m}^{2}$ were deployed at distances of $1 \mathrm{~m}(n=3), 10 \mathrm{~m}(n=3)$, $25 \mathrm{~m}(n=1), 50 \mathrm{~m}(n=1), 100 \mathrm{~m}(n=1), 250 \mathrm{~m}(n=1)$, $500 \mathrm{~m}(n=1)$, and $1,000 \mathrm{~m}(n=1)$ from Lake Mindelsee. We sampled Malaise traps between April 17-24, 2019 and May 1316, 2019. In April, we sampled all traps; in May, we sampled single traps at 1,100, and 1,000 m. We collected all arthropods found in or on (i.e., web-building spiders) Malaise traps live and transported them back to the laboratory, where they were snap-frozen, identified, freeze-dried, weighed, and then stored at $-80^{\circ} \mathrm{C}$ for stable isotope and fatty acid analyses. For analyses of insect biomass, we weighed all freeze-dried insects on either a Mettler-Toledo XP2U ultra-microbalance or a Mettler-Toledo ME104T/00 (for samples over $2.1 \mathrm{~g}$ ).

\section{Dietary Composition}

To understand consumer resource use across distances, we conducted bulk carbon and nitrogen stable isotope analyses on spiders, Blue Tit nestlings and several major groups of potential aquatic and terrestrial insect prey (Supplementary Table 1). We collected blood samples from the branchial veins of nestlings using $27 \mathrm{G}$ needles when they were approximately five days old. All samples were oven-dried at $50^{\circ} \mathrm{C}$ for at least $24 \mathrm{~h}$ prior to being weighed. We weighed out homogenized samples ( $0.5 \mathrm{mg}$ ) of insects, spiders, and nestling blood into tin capsules (IVA Analysetechnik, Meerbusch, Germany). We then quantified bulk carbon and nitrogen stable isotope $\left(\delta^{13} \mathrm{C}\right.$ and $\delta^{15} \mathrm{~N}$ ) values using an A flash HT Plus CNSOH elemental analyzer interfaced with a Conflo IV device (Thermo Co.) to a continuous flow stable isotope ratio mass spectrometer (Delta $\mathrm{V}$ Advantage IRMS, Thermo Co.). Values were normalized against reference gas injections of $\mathrm{N}_{2}$ and $\mathrm{CO}_{2}$ (Messer, Krefeld, Germany) and standardized using international standards USGS24, and IAEA-CH-7 (IAEA, Vienna, Austria), methionine (IVA, Vienna, Austria), and urea (Schimmelmann Research Materials, Bloomington, IN, United States) We did not perform lipid corrections on our samples because previous studies have suggested lipid corrections are necessary only for high fat 
tissues, such as fish and mammal skin and muscle tissues with C:N ratios > 3.5 (Hoffman and Sutton, 2010). Results are expressed in delta $(\delta)$ units with respect to international standards (Vienna Pee Dee Belemnite or $\mathrm{N}_{2}$ air), following the equations: $\delta^{13} \mathrm{C}=\left[\left(\mathrm{R}_{\text {sample }} / \mathrm{R}_{\text {standard }}\right)-1\right] \times 10^{3}$ (expressed in $\left.\% 0\right)$, where $\mathrm{R}$ is ${ }^{13} \mathrm{C} /{ }^{12} \mathrm{C}$ and $\delta^{15} \mathrm{~N}=\left[\left(\mathrm{R}_{\text {sample }} / \mathrm{R}_{\text {standard }}\right)-1\right] \times 10^{3}$ (expressed in $\%$ ), where $\mathrm{R}$ is ${ }^{15} \mathrm{~N} /{ }^{14} \mathrm{~N}$.

To estimate how the proportion of emergent aquatic insects in spider diets varied with distance from Lake Mindelsee, we used Bayesian stable isotope mixing models with the $\mathrm{R}$ package MixSIAR (Stock et al., 2018). We created three source $\delta^{15} \mathrm{~N}$ and $\delta^{13} \mathrm{C}$ models based on stable isotope biplot patterns, which suggested that emergent aquatic insects, caterpillars, and other terrestrial insects were isotopically distinct potential prey sources. We grouped: (1) all aquatic insects together, (2) caterpillars from all distances together, and (3) terrestrial Coleoptera and terrestrial Diptera from all distances together. We used a $\delta^{15} \mathrm{~N}$ trophic discrimination factor (TDF) of 2.75 (standard deviation of $2.2 \%$ ) and a $\delta^{13} \mathrm{C}$ TDF of $0.8 \%$ (standard deviation of $1.9 \%$ ) based on previously estimated spider TDF from Kelly et al. (2015) and Yuen and Dudgeon (2016). We chose not to estimate Blue Tit nestling diets with mixing models based on biplot patterns showing little isotopic differentiation among nestlings based on distance from Lake Mindelsee.

\section{Resource Composition}

To understand the nutritional composition of resources for insectivores, we examined the fatty acid content and composition of emergent aquatic insects and terrestrial insects. We report fatty acid data for composite samples of aquatic insects collected from emergence traps on Lake Mindelsee in AprilMay 2015 (Martin-Creuzburg et al., 2017) and terrestrial insects and spiders collected from Malaise traps in April-May 2019 (Supplementary Table 1). Freeze-dried insects were deposited in $7 \mathrm{~mL}$ dichloromethane:methanol $(2: 1, \mathrm{v}: \mathrm{v})$, crushed using a glass rod, vigorously sonicated, and stored over night at $-20^{\circ} \mathrm{C}$. Total lipids were extracted three times from tissues with dichloromethane:methanol (2:1, v:v). Pooled cell-free lipid extracts were evaporated to dryness under $\mathrm{N}_{2}$-atmosphere and transesterified with methanolic $\mathrm{HCl}\left(3 \mathrm{~mol} / \mathrm{L}, 60^{\circ} \mathrm{C}, 15 \mathrm{~min}\right.$, Sigma-Aldrich 33050-U). Fatty acid methyl esters (FAME) were extracted three times with isohexane $(2 \mathrm{~mL})$. Pooled FAMEcontaining fractions were evaporated to dryness under $\mathrm{N}_{2}$ and resuspended in isohexane $(10-100 \mu \mathrm{L}$, depending on dry mass of insect sample). FAME were analyzed by gas chromatography (GC) using a HP 6890 gas chromatograph (Agilent Technologies) equipped with a flame ionization detector (FID) and a DB-225 [J\&W Scientific, $30 \mathrm{~m} \times 0.25 \mathrm{~mm}$ inner diameter (id) $\times 0.25 \mu \mathrm{m}$ film] capillary column. Configuration details are given elsewhere (Martin-Creuzburg et al., 2010). FAME were quantified by comparison to an internal standard (C23:0 methyl ester) of known concentrations (between 10 and 600 ng depending upon insect dry mass in the sample), using multipoint calibration curves generated using FAME standards (Sigma). FAMEs were identified by their retention times and their mass spectra, which were recorded with a quadrupole gas chromatographmass spectrometer (GC-MS; Agilent Technologies, 5975C inert MSD) equipped with a DB-225MS fused-silica capillary column (J\&W Scientific, $30 \mathrm{~m} \times 0.25 \mathrm{~mm}$ id $\times 0.25 \mu \mathrm{m}$ film); gas chromatographic settings as for FID. Mass spectra were recorded between 50 and $600 \mathrm{~m} / \mathrm{z}$ in the electron ionization (EI) mode. The limit of quantitation was $10 \mathrm{ng}$ of fatty acid, and the absolute amount of each fatty acid was related to the insect or spider dry mass. Results are derived FAME and expressed in $\mu \mathrm{g}$ fatty acid $\mathrm{mg} / \mathrm{dw}$.

\section{Fatty Acid Sources}

Using compound-specific stable isotope analyses (CSIA), we examined how the isotopic composition of PUFA for spiders, nestlings, and insects varied across taxa and with distance from the lake. We conducted CSIA on extracted FAME for Blue Tits nestling livers, and composite samples of spiders and insects (Supplementary Table 1). Terrestrial insects were collected via beating sheets and/or Malaise traps as described previously and emergent aquatic insects were collected from the previously described emergence traps deployed in 2019. We chose to analyze liver from birds because liver is the main site of fatty acid synthesis (e.g., Twining et al., 2018a) and therefore was the tissue that we sampled for our dosing experiment (see below). Terrestrial arthropods were collected and separately analyzed for multiple distances from the lake. FAME were separated using a gas chromatograph (Trace 1310 Thermo Co.) linked to the Delta $\mathrm{V}$ Advantage IRMS via Isolink 2 and Conflo IV (Thermo Co.). A Split/Splitless Liner with Single Taper $(4 \mathrm{~mm} \times 6.3 \mathrm{~mm} \times 78.5 \mathrm{~mm}$, Cat. No. 453A1355, Thermo Co.) was used, the injector temperature was kept at $250{ }^{\circ} \mathrm{C}$ and all samples were injected in splitless mode. For $\delta^{13} \mathrm{C}$, FAME were separated on a VF-WAXm $0 \mathrm{~m} / 0.25 \mathrm{~mm}$ i.d./0.25 $\mu \mathrm{m}$ film thickness column (Agilent Technologies, Santa Clara, CA, United States) at a flow rate of $1.2 \mathrm{~mL} / \mathrm{min}$, followed by oxidation to $\mathrm{CO}_{2}$ in a combustion reactor, filled with $\mathrm{Ni}, \mathrm{Pt}$, and $\mathrm{Cu}$ wires, at a temperature of $1,000^{\circ} \mathrm{C}$. The temperature gradient for $\delta^{13} \mathrm{C}$ analysis started at $80^{\circ} \mathrm{C}$, which was kept for $2 \mathrm{~min}$, after which the temperature was raised by $30^{\circ} \mathrm{C} / \mathrm{min}$ to $175^{\circ} \mathrm{C}$, by $5^{\circ} \mathrm{C} / \mathrm{min}$ to $200^{\circ} \mathrm{C}$ and finally by $2.4^{\circ} \mathrm{C} / \mathrm{min}$ to $250^{\circ} \mathrm{C}$, which was maintained for $30 \mathrm{~min}$. Results are expressed in delta $(\delta)$ units with respect to international standards (Vienna Pee Dee Belemnite), following the equation: $\delta^{13} \mathrm{C}=\left[\left(\mathrm{R}_{\text {sample }} / \mathrm{R}_{\text {standard }}\right)-1\right] \times 10^{3}$ (expressed in $\% 0$ ), where $\mathrm{R}$ is ${ }^{13} \mathrm{C} /{ }^{12} \mathrm{C}$. It should be noted that none of the insects or spiders that we analyzed had sufficient DPA or DHA to measure $\delta^{13} C_{D P A}$ or $\delta^{13} C_{D H A}$.

To understand the nutritional value of $n-3$ LC-PUFA-rich aquatic resources versus n-3 LC-PUFA-poor terrestrial resources for Blue Tit nestlings, we fed ${ }^{13} \mathrm{C}$-enriched ALA to a subset of nestlings and conducted CSIA to determine if nestlings were synthesizing EPA and DHA from ALA. We acquired heavily ${ }^{13} \mathrm{C}$ enriched ALA (all 18 carbons ${ }^{13} \mathrm{C}$-labeled) from Eurisotop, a subsidiary of Cambridge Isotope Labs, which we dissolved into safflower oil and fed $100 \mu \mathrm{L}$ of oil containing approximately $0.196 \mathrm{mg}$ of ${ }^{13} \mathrm{C}$-enriched ALA to 4 nestlings from the same nest and clutch via gavage. Prior to dosing nestlings with ${ }^{13} \mathrm{C}$-enriched 


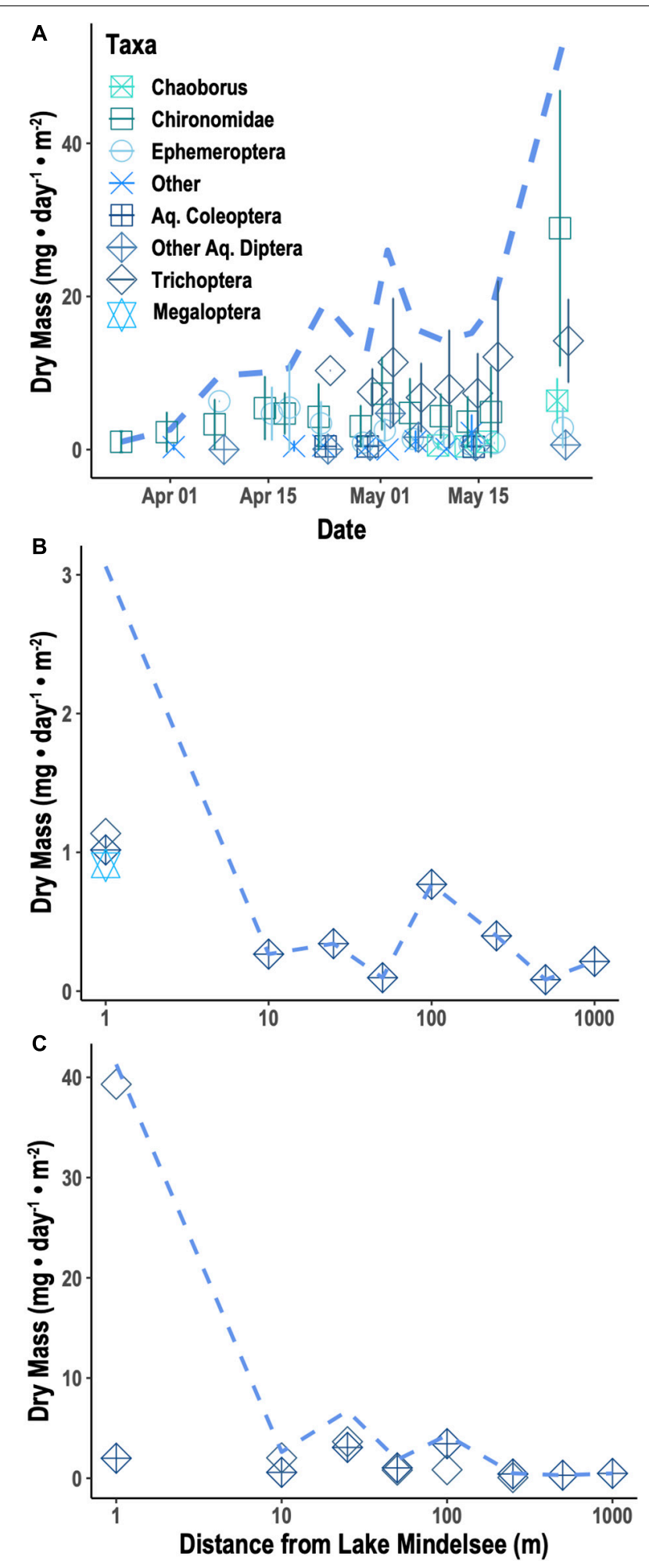

FIGURE 1 | Emergent aquatic insect biomass for individual taxa means (points) and total mean emergent aquatic insect biomass (dashed line) from (A) means ( $\pm 1 \mathrm{SD}$ ) of biomass per taxa from emergence traps, (B) mean biomass of aquatic insects from Malaise traps with distance from Lake Mindelsee in April, and (C) mean biomass of aquatic insects from Malaise traps with distance from Lake Mindelsee in May.
ALA, we also fed 7 nestlings from different nests and clutches the same amount of safflower oil as a control using separate equipment. All nestlings were from nests beside the lake in order to estimate minimum n-3 LC-PUFA synthesis from ALA under conditions of high potential n-3 LC-PUFA availability. Fortyeight hours after dosing, we collected nestlings from the nest by hand, placed them into a muslin bag, and transported them back to the laboratory. In the laboratory, we sacrificed them via cervical dislocation and then rapidly dissected and snap froze livers with dry ice, and then put them into storage at $-80^{\circ} \mathrm{C}$. Prior to performing CSIA, we freeze-dried nestling livers and then extracted fatty acids for CSIA following the methods above.

\section{Data Analysis}

We analyzed variation in arthropod biomass and diversity over time (for emergence trap samples) and space (for Malaise trap samples) using generalized linear models with a Poisson distribution (base R glm function). Specifically, we used either time (i.e, sample collection date) or space (i.e., distance in $\mathrm{m}$ from shoreline) as predictors of the response variables: (1) arthropod biomass and (2) arthropod diversity. We examined spatial variation in: (1) Malaise trap aquatic insect biomass, (2) terrestrial arthropod biomass, and (3) spider biomass. Malaise trap samples collected in April and May were analyzed separately due to the varying sampling regimes between months. We defined emergence trap diversity as the total number of morphotaxa (i.e., taxa grouped together based on morphology) per date and we defined Malaise trap diversity as total number of orders per distance.

To examine variation in ALA, LIN, ARA, EPA, and DHA content between aquatic and terrestrial arthropods captured in emergence traps and Malaise traps, we used generalized linear models using one of two approaches due to zero inflation (base $\mathrm{R}$ glm function). For non-zero inflated data, we subsequently examined taxa-specific differences in fatty acid content using generalized linear models with a Gaussian distribution. However, because DHA content data were zero inflated, we first analyzed data using a binomial distribution treating zeros as zeros and non-zero data as 1 . We then analyzed the subset of non-zero DHA data with a gamma distribution using a log-link function with the function lmer (De Boeck et al., 2011). We combined fatty acid content data from April and May samples to encompass our entire tit and spider sampling season. We also examined spatial variation in spider ALA, LIN, ARA, and EPA content by distance from Lake Mindelsee using Kruskal-Wallace Chi squared tests (base R Kruskal.test function) followed by Dunn tests for multiple comparisons (Dinno and Dinno, 2017).

We compared the $\delta^{13} C_{P U F A}$ values of all emergent aquatic insects versus terrestrial arthropods using Welch's two sample $t$-tests (base $\mathrm{R}$ t.test function). We then examined how $\delta^{13} \mathrm{C}_{P U F A}$ values varied across taxa and distances using Kruskal-Wallis Chi squared tests followed by Dunn tests for multiple comparisons. Finally, we used Kruskal-Wallis Chi squared tests to compare the $\delta^{13} \mathrm{C}_{A L A}, \delta^{13} \mathrm{C}_{E P A}$, and $\delta^{13} \mathrm{C}_{D H A}$ values of Blue Tit nestlings fed ${ }^{13} \mathrm{C}$-enriched ALA with $\delta^{13} \mathrm{C}_{A L A}, \delta^{13} \mathrm{C}_{E P A}$, and $\delta^{13} \mathrm{C}_{D H A}$ values of control nestlings fed only the carrier oil. All statistical analyses 


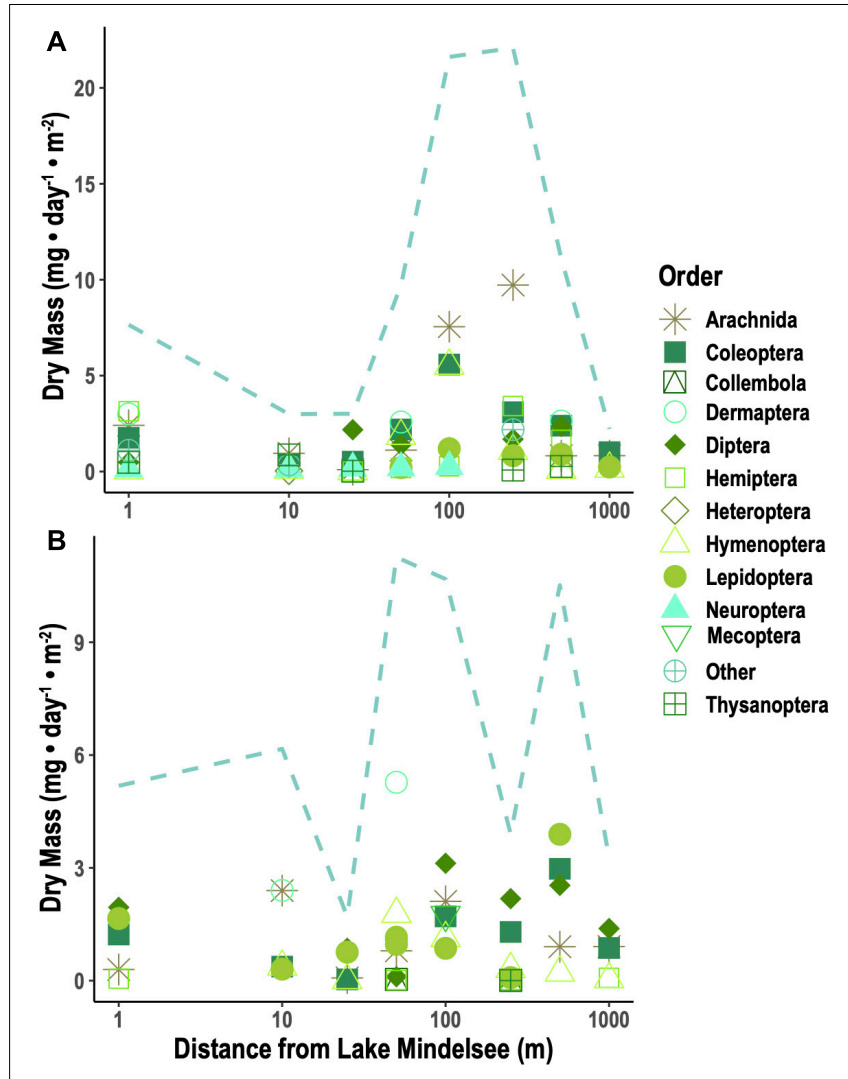

FIGURE 2 | Mean terrestrial arthropod biomass per taxa (points) and sum of mean biomass for all taxa (dotted lines) collected from Malaise traps in

(A) April and (B) May. Lepidoptera include both adult and larval Lepidoptera (i.e., caterpillars) captured in Malaise traps.

were conducted in $\mathrm{R}$, version 4.0.3 and all figures were created in R using ggplot2 (Wickham, 2011).

\section{RESULTS}

\section{Resource Availability}

Caterpillar biomass from beating sheet sampling was highly variable over time and space, showing no clear seasonal trends (Supplementary Figure 1) and no consistent spatial patterns across distances. Emergent aquatic insect biomass increased significantly over the tit breeding season (Figure 1A; null deviance $=109.238$ on 12 degrees of freedom $(\mathrm{df})$, residual deviance $=30.298$ on $11 \mathrm{df}, z=8.350, p<0.0001$ ). Taxonomic diversity of emergent insects sampled from Lake Mindelsee also increased over the season (Figure 1A; null deviance $=10.646$ on $12 \mathrm{df}$, residual deviance $=5.100$ on $11 \mathrm{df}, z=2.305$, $p<0.05)$. Total emergent aquatic insect biomass did not vary with distance from the lake in April (Figure 1B) but did decrease significantly with lake distance during May (Figure 1C; null deviance $=120.577$ on $7 \mathrm{df}$, residual deviance $=61.202$ on $6 \mathrm{df}$, $z=-3.771, p<0.001)$. This distance effect was driven by riparian Trichoptera (Figure 1C), which were also the biomass dominant group of emergent aquatic insects collected from emergence traps during mid-May (Figure 1A). Total terrestrial arthropod biomass (i.e., spiders and terrestrial insects) and spider biomass alone did not vary with distance from the lake during either April or May (Figure 2). Arthropod diversity at the order level did not vary with distance from the lake during either month.

\section{Resource Composition}

The LIN contents of all aquatic taxa versus all terrestrial taxa did not differ significantly (Table 1) between aquatic and terrestrial arthropods (Figure 3A). Among taxa, LIN was significantly higher in Chironomidae, Dermaptera, Hymenoptera, Neuroptera, and "other aquatic Diptera" compared to Chaoborus (Supplementary Table 2). Across taxa, aquatic insects contained significantly more ALA, ARA, EPA, and DHA than terrestrial arthropods (Figures 3B-D and Table 1). Among taxa, Ephemeroptera, Lepidoptera, Thysanoptera, and Trichoptera had significantly higher ALA compared to Chaoborus, while Hemiptera, spiders, and terrestrial Diptera had significantly lower ALA (Figure 3B and Supplementary Table 2). Chaoborus had the highest contents of C20-22 PUFA

TABLE 1 | General linear models of fatty acid content by arthropod habitat origin.

\begin{tabular}{|c|c|c|c|c|}
\hline \multicolumn{5}{|c|}{ LIN by origin (aquatic or terrestrial) } \\
\hline & Estimate & SE & $t$-Value & $p$-Value \\
\hline Intercept & 8.8920 & 0.5330 & 16.683 & $<0.0001$ \\
\hline Terrestrial & -0.3828 & 0.9127 & -0.419 & 0.675 \\
\hline
\end{tabular}

Null deviance: 5543.4 on 172 df Residual deviance: 5537.7 on $171 \mathrm{df}$

ALA by origin (aquatic or terrestrial)

$\begin{array}{lcccc} & \text { Estimate } & \text { SE } & \boldsymbol{t} \text {-Value } & \boldsymbol{p} \text {-Value } \\ \text { Intercept } & 8.8405 & 0.5247 & 16.847 & <0.0001 \\ \text { Terrestrial } & \mathbf{- 4 . 2 4 2 0} & \mathbf{0 . 8 9 8 6} & \mathbf{- 4 . 7 2 1} & <\mathbf{0 . 0 0 0 1}\end{array}$

Null deviance: 6067.4 on $172 \mathrm{df} \quad$ Residual deviance: 5367.8 on $171 \mathrm{df}$

ARA by Origin (Aquatic or Terrestrial)

$\begin{array}{lcccc} & \text { Estimate } & \text { SE } & t \text {-Value } & p \text {-Value } \\ \text { Intercept } & 2.9552 & 0.2041 & 14.480 & <0.0001 \\ \text { Terrestrial } & \mathbf{- 2 . 0 9 4 5} & \mathbf{0 . 3 4 9 5} & \mathbf{- 5 . 9 9 3} & <\mathbf{0 . 0 0 0 1}\end{array}$

Null deviance: 982.48 on $172 \mathrm{df} \quad$ Residual deviance: 811.92 on $171 \mathrm{df}$

EPA by origin (aquatic or terrestrial)

$\begin{array}{lcccc} & \text { Estimate } & \text { SE } & t \text {-Value } & p \text {-Value } \\ \text { Intercept } & 20.904 & 1.029 & 20.32 & <0.0001 \\ \text { Terrestrial } & \mathbf{- 1 9 . 1 5 9} & \mathbf{1 . 7 6 2} & \mathbf{- 1 0 . 8 7} & <\mathbf{0 . 0 0 0 1}\end{array}$

Null deviance: 34907 on 172 df Residual deviance: 20637 on 171 df

DHA by origin binomial (aquatic or terrestrial)

$\begin{array}{lcccc} & \text { Estimate } & \text { SE } & z \text {-Value } & p \text {-Value } \\ \text { Intercept } & -1.2192 & 0.2232 & -5.462 & <0.0001 \\ \text { Terrestrial } & \mathbf{- 2 . 1 3 0 7} & \mathbf{0 . 7 5 3 2} & \mathbf{- 2 . 8 2 9} & \mathbf{0 . 0 0 4 6 7}\end{array}$

Null deviance: 153.18 on $172 \mathrm{df} \quad$ Residual deviance: 139.89 on $171 \mathrm{df}$

DHA by origin non-zero values (aquatic or terrestrial)

$\begin{array}{lcccc} & \text { Estimate } & \text { SE } & t \text {-Value } & p \text {-Value } \\ \text { Intercept } & 1.6893 & 0.1123 & 5.047 & <0.0001 \\ \text { Terrestrial } & \mathbf{- 1 . 0 3 3 6} & \mathbf{0 . 4 2 0 1} & \mathbf{- 2 . 4 6 1} & \mathbf{0 . 0 2 0 8}\end{array}$

Null deviance: 17.793 on $172 \mathrm{df} \quad$ Residual deviance: 16.297 on $171 \mathrm{df}$

Bold values indicate variables that were statistically significant at the alpha $=0.05$ level. 
with the exception of EPA in Ephemeroptera (Figures 3C,D and Supplementary Table 2). ARA was significantly lower in all taxa relative to Chaoborus (Figure 3C and Supplementary Table 2). There were no taxa-based differences in whether or not DHA was zero/below our detection limits or greater than zero/above our detection limit, but, among taxa with non-zero DHA, Chironomidae, Mecoptera, and 'other aquatic Diptera' had significantly lower DHA relative to Chaoborus (Supplementary Table 2 and Figure 3).

\section{Dietary Patterns}

Spiders within the riparian zone had $\delta^{15} \mathrm{~N}$ values that were much higher than those of spiders at the 500 or $1,000 \mathrm{~m}$ distances and were similar or slightly higher than those of emergent aquatic insects (Figure 4). Mixing models estimated that approximately $74 \%$ of riparian spider diet was composed of emergent aquatic insects (Supplementary Table 3). Riparian spiders likely consumed large Trichoptera (Limnophilidae), Ephemeroptera, and Chironomidae rather than Chaoborus or smaller Trichoptera (Figure 4). Spiders at the 500 and 1,000 m distances had stable isotope values that were nearly identical to those of tit nestlings (Figure 4). Mixing models estimated that inland spiders consumed 43 and $60 \%$ caterpillars and 54 and $39 \%$ other terrestrial insects, for spiders at the 500 and 1,000 m distances, respectively (Supplementary Table 3).

In contrast to spiders, Blue Tit nestlings consumed relatively consistent diets, regardless of their distance from the lake (Figure 4). Nestlings did not appear to consume substantial quantities of either emergent aquatic insects or caterpillars. Aquatic insects had $\delta^{15} \mathrm{~N}$ values that were substantially higher than or equivalent to those of tits, but much more depleted in $\delta^{13} \mathrm{C}$, making them unlikely prey sources (Figure 4). Chaoborus and some of the chironomids had highly depleted $\delta^{13} \mathrm{C}$ values. Like inland spiders (Supplementary Table 3), Blue Tit nestlings appeared to rely more upon a mix of terrestrial flies, beetles, as well as some spiders at the 500 and 1,000 m distances (Figure 4).

\section{Fatty Acid Sources}

Mean emergent aquatic insect $\delta^{13} \mathrm{C}_{L I N}, \delta^{13} \mathrm{C}_{A L A}, \delta{ }^{13} \mathrm{C}_{A R A}$, and $\delta^{13} \mathrm{C}_{E P A}$ values were significantly lower than the mean values of most terrestrial arthropods (Figure 5; LIN: $t=3.7779$, $\mathrm{df}=60.88$, $p<0.001$; ALA: $t=4.8804$, df $=39.042, p<0.001$; ARA: $t=8.1614, \mathrm{df}=39.998, p<0.001$; EPA: $t=3.9865, \mathrm{df}=55.12$, $p<0.001)$. Within emergent aquatic insects, Ephemeroptera and Chironomidae both had significantly lower $\delta^{13} \mathrm{C}_{L I N}$ values than Trichoptera (Figure 5A; Kruskal-Wallis chi-squared $=9.8255$, $\mathrm{df}=2, p=0.01)$. Chaoborus had significantly lower $\delta^{13} \mathrm{C}_{A L A}$ values than Chironomidae (Figure 5B; Kruskal-Wallis chisquared $=4.587$, df $=3, p=0.2047$, Dunn test ChaoborusChironomidae $p<0.05)$. Ephemeroptera also had significantly lower $\delta^{13} \mathrm{C}_{A R A}$ values than Chironomidae (Figure 5C; KruskalWallis chi-squared $=4.7988$, $\mathrm{df}=2, p=0.09077$, Dunn test Ephemeroptera-Chironomidae $p<0.05) . \delta^{13} \mathrm{C}_{E P A}$ values did not differ significantly among emergent aquatic insect taxa (Figure 5D).

Caterpillars had significantly lower $\delta^{13} C_{L I N}$ and $\delta^{13} C_{E P A}$ values than other terrestrial arthropods (Figures 5A,D; LIN: Kruskal-Wallis chi-squared $=24.918$, df $=3, p<0.001$; EPA:
Kruskal-Wallis chi-squared $=19.625$, df $=3, p<0.001$ ). Caterpillar $\delta^{13} \mathrm{C}_{A L A}$ values were significantly lower within the riparian zone compared to those $500 \mathrm{~m}$ inland (Figure 5B; Kruskal-Wallis chi-squared $=6.432$, $\mathrm{df}=2, p=0.04012$ ) whereas terrestrial Diptera $\delta^{13} \mathrm{C}_{A L A}$ were significantly higher in the riparian zone relative to those 500 and $1,000 \mathrm{~m}$ inland (Figure 5B; Kruskal-Wallis chi-squared $=4.5$, $\mathrm{df}=2, p=0.1054$, Dunn test Riparian-1000 $p<0.05$, Riparian-500 m $p<0.05$ ) and riparian terrestrial Diptera $\delta{ }^{13} \mathrm{C}_{\text {LIN }}$ values were significantly higher than those 1,000 $\mathrm{m}$ inland (Figure 5B; Kruskal-Wallis chisquared $=3.4583, \mathrm{df}=2, p=0.1774$, Dunn test Riparian-1000 m $p<0.05)$.

Spider $\delta^{13} \mathrm{C}_{\text {LIN }}$ and $\delta^{13} \mathrm{C}_{A R A}$ values did not vary across distances, but riparian spiders had significantly more negative $\delta^{13} \mathrm{C}_{A L A}$ and $\delta^{13} \mathrm{C}_{E P A}$ values compared to spiders at the $1,000 \mathrm{~m}$ distance (Figure 5; Kruskal-Wallis chi-squared $=3.927, \mathrm{df}=2$, $p_{1000 m \text {-Riparian }}<0.05 ;$ Kruskal-Wallis chi-squared $=5.067, \mathrm{df}=2$,

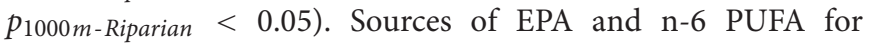
Blue Tit nestlings were similar across distances (Figure 5). Across distances, nestling $\delta^{13} \mathrm{C}_{A L A}$ values were significantly more negative for nestlings at the $1,000 \mathrm{~m}$ distance compared to those within the riparian zone (Figure 5B; Kruskal-Wallis chisquared $=3.473, \mathrm{df}=2, p_{1000 m \text {-Riparian }}=0.032$ ), while nestling DPA and DHA values were significantly more negative for nestlings within the riparian zone compared to those at the 500 $\mathrm{m}$ distance (DPA: Kruskal-Wallis chi-squared $=4.043$, $\mathrm{df}=2$, $p_{500 m \text {-Riparian }}<0.05$; DHA: Kruskal-Wallis chi-squared $=9.336$, $\left.\mathrm{df}=2, p_{500 m \text {-Riparian }}<0.01\right)$.

Blue Tit nestlings dosed with ${ }^{13} \mathrm{C}$-enriched ALA had significantly enriched $\delta^{13} \mathrm{C}_{A L A}$ and $\delta^{13} \mathrm{C}_{D H A}$ compared to control nestlings (Figure 6; ALA: Kruskal-Wallis chi-squared = 7, $\mathrm{df}=1$, $p<0.01$; DHA: Kruskal-Wallis chi-squared = 7, $\mathrm{df}=1, p<0.01$ ), but $\delta^{13} C_{E P A}$ values did not vary significantly between dosed and control nestlings (Figure 6; Kruskal-Wallis chi-squared $=2.2857$, $\mathrm{df}=1, p=0.13)$.

\section{DISCUSSION}

To understand the degree to which habitat generalists take advantage of aquatic subsidies of n-3 LC-PUFA, we examined dietary resources and PUFA sources for web-building spiders and Blue Tit nestlings along a riparian to inland gradient from a lake. As expected, emergent aquatic insect biomass fluxes were highest directly over the lake, as well as in the riparian area in May, compared to further inland whereas terrestrial arthropod biomass fluxes did not vary spatially with distance from Lake Mindelsee. We found that riparian spiders consumed emergent aquatic insects and likely relied upon them as sources of ALA and EPA. Blue Tit nestlings, in contrast, consumed terrestrial arthropod-based diets, regardless of emergent aquatic insect prey availability and distance from the lake. Tit nestlings relied upon internal synthesis as a source of the n-3 LC-PUFA DHA and did not appear to use emergent aquatic insects as a source of n-3 LC-PUFA, even in riparian habitats.

Web-building spiders consumed EPA-rich emergent aquatic insects in riparian habitats and EPA-poor terrestrial prey in inland habitats 500-1000 m from the lakeshore (Figures 3,4 and 


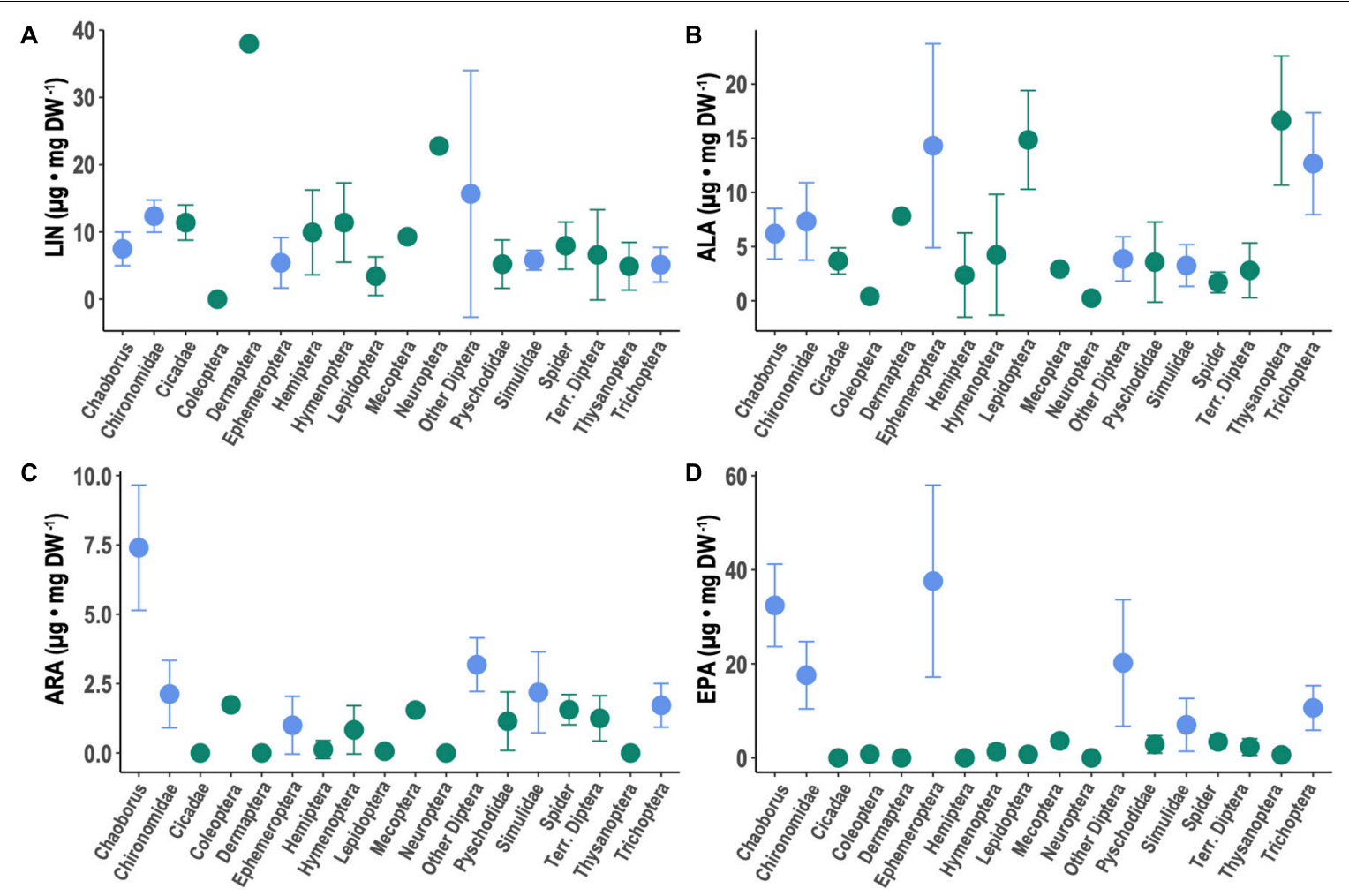

FIGURE 3 | Content of selected PUFA in aquatic (blue) and terrestrial (green) insect taxa as well as spiders: (A) linoleic acid (LIN; 18:2n-6), (B) $\alpha$-linolenic acid (ALA; 18:3n-3), (C) arachidonic acid (ARA; 20:4n-6), and (D) eicosapentaenoic acid (EPA; 20:5n-3). Data represent composite means ( \pm 1 SD). Data on aquatic insects are from Martin-Creuzburg et al. (2017). Lepidoptera here are larval Lepidoptera (i.e., caterpillars).

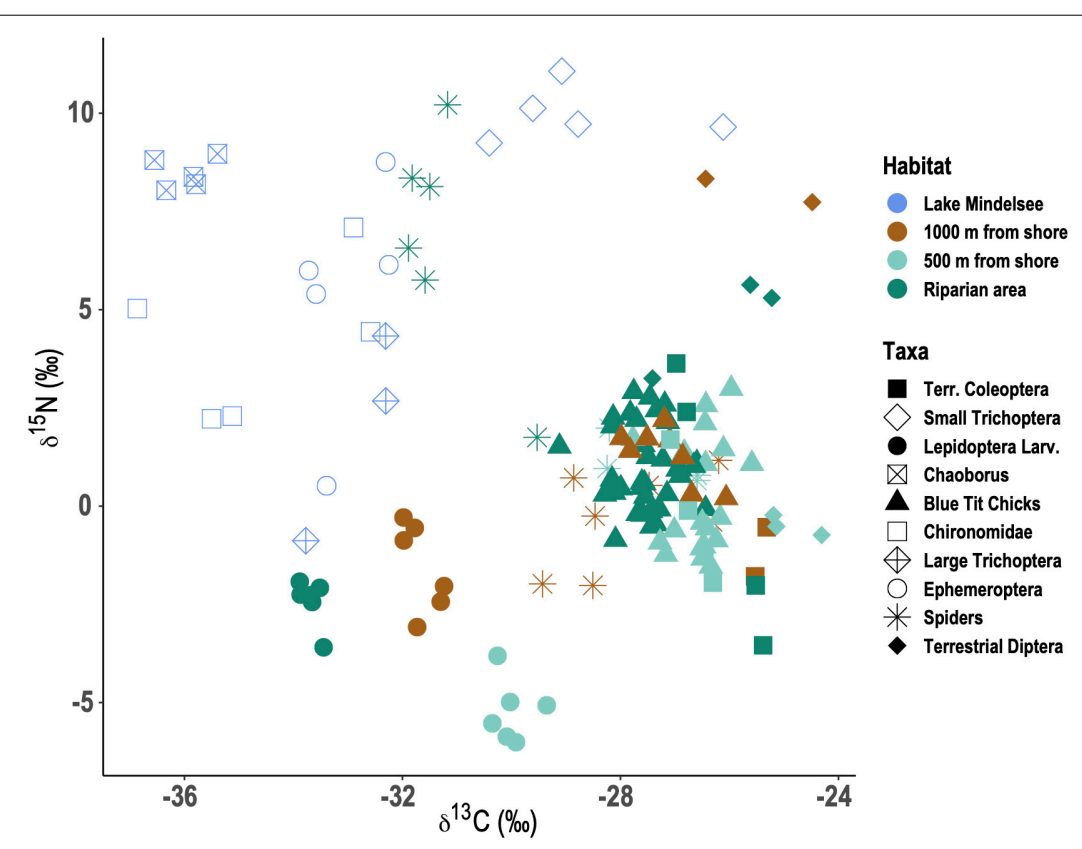

FIGURE 4 | Bulk nitrogen stable isotope $\left(\delta^{15} \mathrm{~N}\right)$ and carbon stable isotope $\left(\delta^{13} \mathrm{C}\right)$ values for aquatic and terrestrial taxa emerging from and found at three distances from Lake Mindelsee (i.e., the riparian area, $\sim 500 \mathrm{~m}$ from shore, and $\sim 1,000 \mathrm{~m}$ from shore). Colors indicate habitat origin of taxa (aquatic or terrestrial) and distance from Lake Mindelsee for terrestrial taxa. Lepidoptera here are larval Lepidoptera (i.e., caterpillars). 

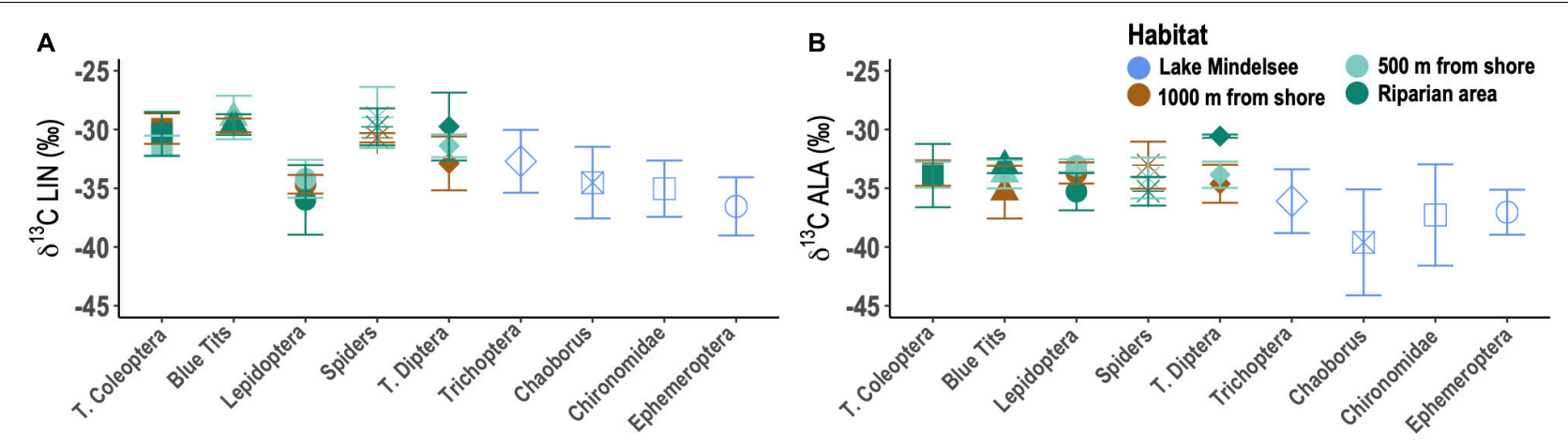

C

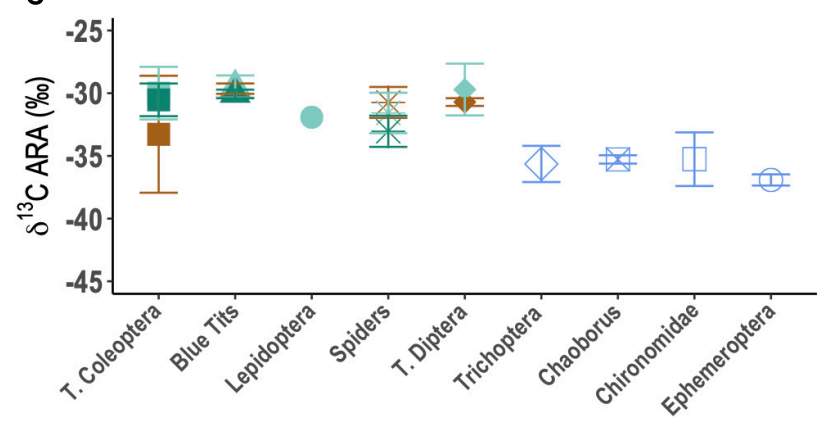

D

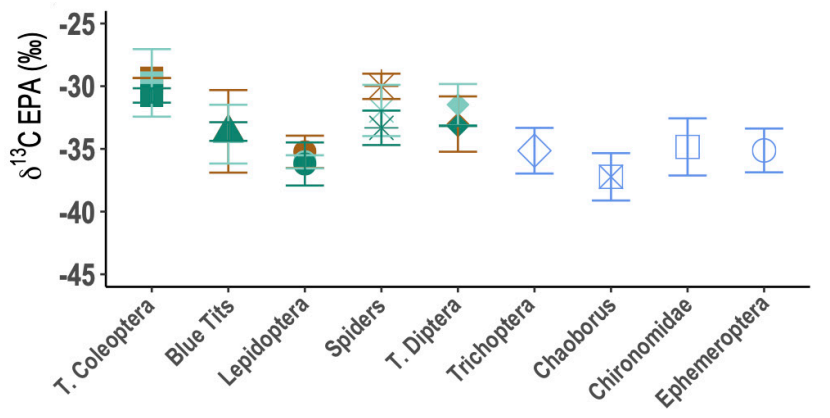

FIGURE 5 | Carbon stable isotope $\left(\delta^{13} \mathrm{C}\right)$ values for (A) linoleic acid (LIN), (B) $\alpha$-linolenic acid (ALA), (C) arachidonic acid (ARA), and (D) eicosapentaenoic acid (EPA). Lepidoptera here are larval Lepidoptera (i.e., caterpillars).

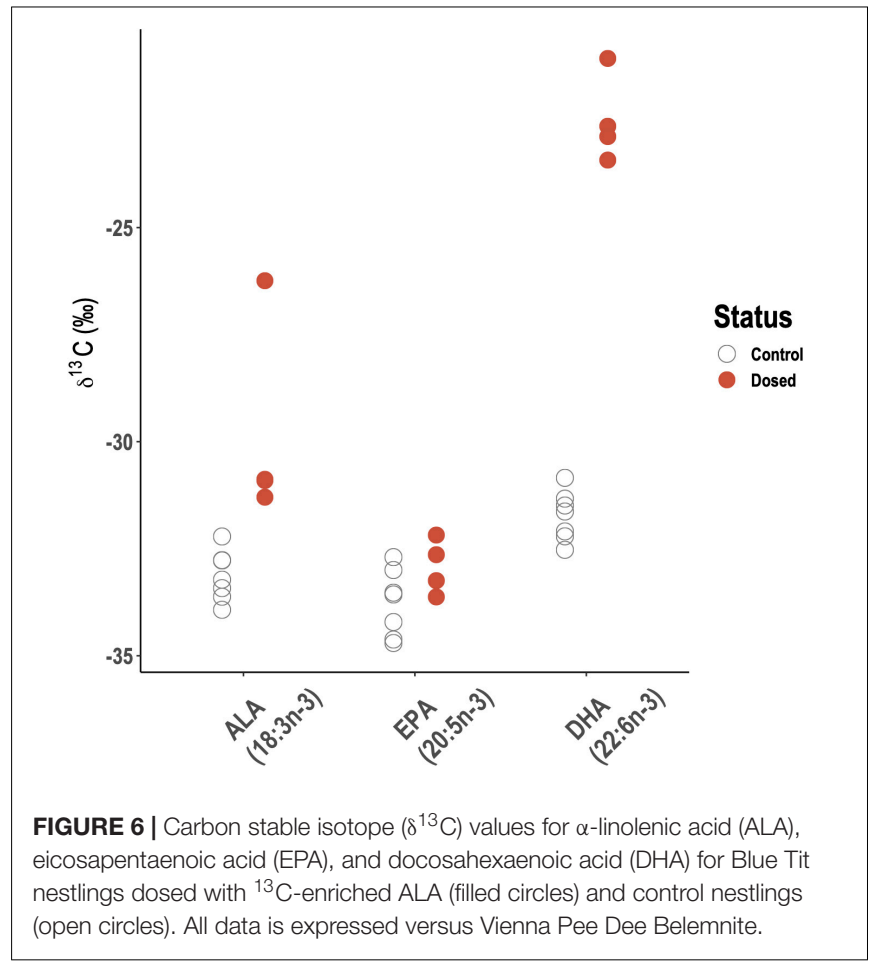

Supplementary Table 3). Riparian spiders likely derived their EPA from aquatic rather than terrestrial sources (Figure 5D), reflecting the higher EPA content and higher percent EPA in emergent aquatic insects compared to terrestrial insects in our study as well as in previous studies (Martin-Creuzburg et al., 2017; Twining et al., 2019). The $\delta^{13} \mathrm{C}_{A L A}$ values of riparian spiders were over $5 \%$ more negative than those of terrestrial flies and overlapped with those of several aquatic taxa (Figure 5B), suggesting that riparian spiders may have derived some of their ALA from emergent aquatic insects, which had significantly more ALA than terrestrial insects. In contrast, spiders at all distances likely obtained the n-6 PUFA LIN and ARA from terrestrial insects, as shown by the less pronounced isotopic overlap between spider and emergent aquatic insect $\delta^{13} \mathrm{C}_{L I N}$ and $\delta^{13} C_{A R A}$ values across all distances (Figures $5 \mathrm{~A}, \mathrm{C}$ ). LIN is typically available in both terrestrial and aquatic insects (e.g., Mathieu-Resuge et al., unpublished; Martin-Creuzburg et al., 2017), including in our study (Figure 3A), which fits with our expectations that aquatic prey would be nutritionally distinct from terrestrial prey in terms of their $n-3$, but not n-6 PUFA content.

Our finding that riparian and inland spider diets vary with distance from aquatic habitats generally echoes those of other recent studies on spider diets and PUFA sources at varying distances from streams (Chari et al., 2020; Kowarik et al., 2021) and lakes (Mathieu-Resuge et al., unpublished). MathieuResuge et al. (unpublished) reported that web-building spiders collected directly on emergence traps and those collected in terrestrial habitats at distances of $1-150 \mathrm{~m}$ from shore had different diet sources. They found that spiders collected above lake traps, like our riparian spiders, most likely obtained EPA directly from EPA-rich emergent aquatic insects, whereas spiders from terrestrial habitats obtained almost all their EPA through bioconversion from dietary ALA, i.e., from terrestrial insects. In 
contrast, our inland spiders appeared able to obtain their EPA either directly from terrestrial insect prey, especially terrestrial Coleoptera, likely through preferential retention, or indirectly from bioconversion of dietary ALA from terrestrial sources. Kowarik et al. (2021) found that ground-dwelling as well as web-building spiders likely consumed emergent aquatic insects within the riparian zone, and that both types of spiders consumed terrestrial insects in inland habitats. They also found that spiders were able to maintain similar EPA content in riparian habitats regardless of their foraging mode, but that spider EPA content declined with distance from shore (Kowarik et al., 2021).

While web-building riparian spiders mostly consumed emergent aquatic insect as a source of EPA, tit nestlings did not appear to take advantage of aquatic prey either directly or indirectly. Previous research suggests that tits typically feed their nestlings largely caterpillar-based diets, with minor proportions of spiders (Royama, 1970; Naef-Daenzer et al., 2000; Isaksson et al., 2015), and that tit breeding phenology and success are directly related to caterpillar availability (e.g., Visser et al., 2006; García-Navas and Sanz, 2011; Simmonds et al., 2020). However, contrary to our expectations, based upon previous studies (NaefDaenzer et al., 2000; Nilsson and Källander, 2006), that caterpillar biomass would increase over the course of the tit breeding season as deciduous trees leafed out, we found no clear seasonal trends in caterpillar biomass (Supplementary Figure 2). We also found no evidence of consistent spatial variation in caterpillar or spider biomass (Supplementary Figure 2 and Figures 2A,B), suggesting that these metrics of habitat quality for tits did not differ with distance from the lake (Riddington and Gosler, 1995; Wilkin et al., 2009; Isaksson et al., 2015). Our bulk stable isotope results suggested that nestlings generally relied upon terrestrial Coleoptera, Diptera, and some spiders (Figures 3A,B). Caterpillars at all distances from the lake had highly depleted bulk $\delta^{13} \mathrm{C}$ values compared to nestlings $\left({ }^{13} \mathrm{C}\right.$ depleted by $3-6 \%$ relative to nestlings) as well as other terrestrial insects, making it unlikely that nestlings consumed a substantial proportion of caterpillars (Figure 4). Our finding reveals that tits feed their nestlings a much greater diversity of prey than previously documented, especially in systems where caterpillars are not highly abundant and/or their peak biomass does not correspond with the tit breeding season.

We also expected that Blue Tit nestlings within the riparian zone would opportunistically consume n-3 LC-PUFA-rich aquatic resources directly or indirectly through predating on spiders that had consumed aquatic prey. Previous studies suggest that Blue Tits occasionally consume emergent aquatic insects, particularly Diptera (e.g., Blondel et al., 1991; Rytkönen et al., 2019; Shutt et al., 2020). However, we found little evidence that riparian nestlings consumed either riparian spiders or the emergent aquatic insects that riparian spiders themselves preyed upon (Figure 4). Although aquatic insects contained significantly more ARA and EPA than terrestrial insects, Blue Tit nestling ARA and EPA, as well as their precursors ALA and LIN, all appeared to be of terrestrial origin or, in the case of ARA and EPA, the result of internal biosynthesis. Blue Tit EPA sources, like overall diet, were highly consistent across distances and likely included terrestrial Coleoptera, terrestrial Diptera, and spiders (Figure 5D). This suggests that tit nestling diet breadth, while broader here than in previous studies, may be limited to prey that adults can easily glean from vegetation to feed their chicks rather than aerial emergent aquatic insects. For example, Schilke et al. (2020) found little relationship between Black-capped Chickadee (Poecile atricapillus) abundance, a functionally equivalent North American relative of the Blue Tit, and emergent aquatic insects. In addition, as we did not sample adult Blue Tits, we cannot exclude the possibility that riparian adults themselves may have consumed aquatic insects, but fed their chicks different prey of terrestrial origin.

Our labeling experiment suggested that Blue Tit nestlings are readily able to convert dietary ALA into DHA through internal synthesis. Interestingly, we found that the $\delta^{13} \mathrm{C}_{D H A}$ values of ${ }^{13} \mathrm{C}$ dosed nestlings were much more heavily labeled than $\delta^{13} \mathrm{C}_{A L A}$ values, suggesting that nestlings rapidly converted nearly all available ${ }^{13} \mathrm{C}$-labeled ALA into DHA. This finding provides a key contrast with those from recent studies of riparian aerial insectivore nestlings. For example, regardless of the proportion of emergent aquatic insects in their diets, Eastern Phoebe nestlings across the landscape likely derive most of their EPA from EPArich aquatic insects (Twining et al., 2019). Tree Swallow nestlings also have limited EPA and DHA synthesis ability, suggesting that they must also derive their n-3 LC-PUFA through aquatic pathways (Twining et al., 2018a). These species are both aerial insectivores that capture flying emergent aquatic insect prey. In contrast, Blue Tits and other gleaners, despite being habitat generalists, may have less dietary flexibility because their foraging behavior does not typically permit them to take advantage of emergent aquatic prey. We found that Blue Tit nestlings use a metabolic (i.e., fatty acid synthesis), rather than a behavioral, foraging-based strategy to fulfill their n-3 LC-PUFA needs.

Consumers can employ metabolic and/or behavioral means to satisfy their requirements for organic compounds like n-3 LCPUFA. Across species, increased access to dietary n-3 LC-PUFA due to habitat preferences, foraging ecology, and/or trophic position is generally associated with reduced n-3 LC-PUFA synthesis ability (Twining et al., 2021). Here, we demonstrated that trade-offs between behavioral versus metabolic n-3 LCPUFA acquisition strategies can also occur within species as the result of flexibility in diet and metabolism. Even in riparian habitats, where EPA-rich emergent aquatic prey were readily available during the breeding season, tit nestlings appeared to derive their DHA via conversion from dietary ALA. Compared with Blue Tit nestlings, web-building spiders displayed striking habitat-based flexibility in their overall diet and PUFA sources between riparian and inland habitats. The differences between Blue Tits and web-building spiders, both habitat generalists, likely resulted from their relative abilities to opportunistically use aerial aquatic insect prey within riparian areas. Web-building spiders passively capture and consume prey that fly, float, or crawl into their webs, whereas Blue Tits actively and selectively forage for prey on vegetation. Past studies examining the n3 LC-PUFA sources and needs of consumers have highlighted the importance of foraging habitat as a selective force upon n3 LC-PUFA internal synthesis ability (e.g., Twining et al., 2021). Our current study highlights the importance of considering consumer foraging strategy when examining the nutritional metabolism of consumers. 


\section{DATA AVAILABILITY STATEMENT}

The raw data supporting the conclusions of this article will be made available by the authors, without undue reservation.

\section{ETHICS STATEMENT}

The animal study was reviewed and approved by Regierungspräsidium Freiburg.

\section{AUTHOR CONTRIBUTIONS}

CT and DM-C designed the study. CT, DM-C, and MK acquired funding. CT, JS, TP, and DM-C conducted fieldwork. CT and TP conducted laboratory analyses. CT and JS analyzed data. CT led writing of the manuscript. All authors contributed to manuscript drafts and gave final approval for publication.

\section{REFERENCES}

Baxter, C. V., Fausch, K. D., and Saunders, W. C. (2005). Tangled webs: reciprocal flows of invertebrate prey link streams and riparian zones. Freshw. Biol. 50, 201-220. doi: 10.1111/j.1365-2427.2004.01328.x

Berzins, L. L., Mazer, A. K., Morrissey, C. A., and Clark, R. G. (2021). Pre-fledging quality and recruitment in an aerial insectivore reflect dynamics of insects, wetlands and climate. Oecologia 196, 89-100. doi: 10.1007/s00442-021-04 918-7

Blondel, J., Dervieux, A., Maistre, M., and Perret, P. (1991). Feeding ecology and life history variation of the blue tit in Mediterranean deciduous and sclerophyllous habitats. Oecologia 88, 9-14. doi: 10.1007/bf00328397

Brenna, J. T., and Carlson, S. E. (2014). Docosahexaenoic acid and human brain development: evidence that a dietary supply is needed for optimal development. J. Hum. Evol. 77, 99-106. doi: 10.1016/j.jhevol.2014.02.017

Chari, L. D., Richoux, N. B., Moyo, S., and Villet, M. H. (2020). Dietary fatty acids of spiders reveal spatial and temporal variations in aquatic-terrestrial linkages. Food Webs 24:e00152. doi: 10.1016/j.fooweb.2020.e00152

Coogan, S. C. P., Raubenheimer, D., Stenhouse, G. B., Coops, N. C., and Nielsen, S. E. (2018). Functional macronutritional generalism in a large omnivore, the brown bear. Ecol. Evol. 8, 2365-2376. doi: 10.1002/ece3.3867

Costello, C. M., Cain, S. L., Pils, S., Frattaroli, L., Haroldson, M. A., and van Manen, F. T. (2016). Diet and macronutrient optimization in wild ursids: a comparison of grizzly bears with sympatric and allopatric black bears. PLoS One 11:e0153702. doi: 10.1371/journal.pone.0153702

De Boeck, P., Bakker, M., Zwitser, R., Nivard, M., Hofman, A., Tuerlinckx, F., et al. (2011). The estimation of item response models with the lmer function from the lme4 package in R. J. Stat. Softw. 39, 1-28.

Dinno, A., and Dinno, M. A. (2017). Package 'dunn. Test'. CRAN Repos 10, 1-7.

Dodson, J. C., Moy, N. J., and Bulluck, L. P. (2016). Prothonotary warbler nestling growth and condition in response to variation in aquatic and terrestrial prey availability. Ecol. Evol. 6, 7462-7474. doi: 10.1002/ece3.2400

Durbin, A. G., Nixon, S. W., and Oviatt, C. A. (1979). Effects of the spawning migration of the alewife, Alosa pseudoharengus, on freshwater ecosystems. Ecology 60, 8-17. doi: 10.2307/1936461

Flecker, A. S., McIntyre, P. B., Moore, J. W., Anderson, J. T., Taylor, B. W., and Hall, R. O. (2010). Migratory fishes as material and process subsidies in riverine ecosystems. Am. Fish. Soc. Symp. 73, 559-592.

Fritz, K. A., Kirschman, L. J., McCay, S. D., Trushenski, J. T., Warne, R. W., and Whiles, M. R. (2017). Subsidies of essential nutrients from aquatic

\section{FUNDING}

CT was supported by the Alexander von Humboldt Foundation. This study was also funded by the Austrian Science Fund (FWF; I 3855-B25) and the German Research Foundation (DFG; MA 5005/8-1) within the framework of the DACH collaboration (project 'AquaTerr'). Conservation area and animal ethics permits 55-8852.15/05 and 35-9185.81/G-19/11 for this study were obtained from the Regierungspräsidium Freiburg.

\section{ACKNOWLEDGMENTS}

We thank K. Winter and M. Pilecky for laboratory assistance.

\section{SUPPLEMENTARY MATERIAL}

The Supplementary Material for this article can be found online at: https://www.frontiersin.org/articles/10.3389/fevo.2021. 735350/full\#supplementary-material

environments correlate with immune function in terrestrial consumers. Freshw. Sci. 36, 893-900. doi: 10.1086/694451

García-Navas, V., and Sanz, J. (2011). The importance of a main dish: nestling diet and foraging behaviour in Mediterranean Blue Tits in relation to prey phenology. Oecologia 165, 639-649. doi: 10.1007/s00442-010-1858-z

Gregory, M. K., and James, M. J. (2014). Functional characterization of the duck and Turkey fatty acyl elongase enzymes ELOVL5 and ELOVL2. J. Nutr. 144, 1234-1239. doi: 10.3945/jn.114.194159

Hixson, S. M., Sharma, B., Kainz, M. J., Wacker, A., and Arts, M. T. (2015). Production, distribution, and abundance of long-chain omega-3 polyunsaturated fatty acids: a fundamental dichotomy between freshwater and terrestrial ecosystems. Environ. Rev. 23, 414-424. doi: 10.1139/er-2015-0029

Hoffman, J. C., and Sutton, T. T. (2010). Lipid correction for carbon stable isotope analysis of deep-sea fishes. Deep Sea Res. I 57, 956-964. doi: 10.1016/j.dsr.2010. 05.003

Isaksson, C., Hanson, M. A., and Burdge, G. C. (2015). The effects of spatial and temporal ecological variation on fatty acid compositions of wild great tits Parus major. J. Avian Biol. 46, 245-253. doi: 10.1111/jav.00409

Jing, M., Gakhar, N., Gibson, R., and House, J. (2013). Dietary and ontogenic regulation of fatty acid desaturase and elongase expression in broiler chickens. Prostaglandins Leukot. Essent. Fatty Acids 89, 107-113. doi: 10.1016/j.plefa. 2013.05.006

Katan, T., Caballero-Solares, A., Taylor, R. G., Rise, M. L., and Parrish, C. C. (2019). Effect of plant-based diets with varying ratios of omega 6 to omega 3 fatty acids on growth performance, tissue composition, fatty acid biosynthesis and lipid-related gene expression in Atlantic salmon (Salmo solar). Comp. Biochem. Physiol. D Genomics Proteomics 30, 290-304. doi: 10.1016/j.cbd.2019. 03.004

Kato, C., Iwata, T., and Wada, E. (2004). Prey use by web-building spiders: stable isotope analyses of trophic flow at a forest-stream ecotone. Ecol. Res. 19, 633-643. doi: 10.1111/j.1440-1703.2004.00678.x

Kautza, A., and Sullivan, S. M. P. (2016). The energetic contributions of aquatic primary producers to terrestrial food webs in a mid-size river system. Ecology 97, 694-705.

Kawaguchi, Y., Taniguchi, Y., and Nakano, S. (2003). Terrestrial invertebrate inputs determine the local abundance of stream fishes in a forested stream. Ecology 84, 701-708. doi: 10.1890/0012-9658(2003)084[0701:tiidtl]2.0.co;2

Kelly, S. P., Cuevas, E., and Ramírez, A. (2015). Stable isotope analyses of webspinning spider assemblages along a headwater stream in Puerto Rico. PeerJ 3:e1324. doi: $10.7717 /$ peerj.1324 
Kowarik, C., Martin-Creuzburg, D., and Robinson, C. T. (2021). Cross-ecosystem linkages: transfer of polyunsaturated fatty acids from streams to riparian spiders via emergent insects. Front. Ecol. Evol. 9:707570. doi: 10.3389/fevo.2021.707570

Lam, M. M.-Y., Martin-Creuzburg, D., Rothhaupt, K.-O., Safi, K., Yohannes, E., and Salvarina, I. (2013). Tracking diet preferences of bats using stable isotope and fatty acid signatures of faeces. PLoS One 8:e83452. doi: 10.1371/journal. pone.0083452

Marcarelli, A. M., Baxter, C. V., Mineau, M. M., and Hall, R. O. (2011). Quantity and quality: unifying food web and ecosystem perspectives on the role of resource subsidies in freshwaters. Ecology 92, 1215-1225. doi: 10.1890/10-2 240.1

Martin-Creuzburg, D., Kowarik, C., and Straile, D. (2017). Cross-ecosystem fluxes: export of polyunsaturated fatty acids from aquatic to terrestrial ecosystems via emerging insects. Sci. Total Environ. 577, 174-182. doi: 10.1016/j.scitotenv. 2016.10.156

Martin-Creuzburg, D., Wacker, A., and Basen, T. (2010). Interactions between limiting nutrients: consequences for somatic and population growth of Daphnia magna. Limnol. Oceanogr. 55, 2597-2607. doi: 10.4319/lo.2010.55. 6.2597

Naef-Daenzer, L., Naef-Daenzer, B., and Nager, R. G. (2000). Prey selection and foraging performance of breeding great tits Parus major in relation to food availability. J. Avian Biol. 31, 206-214. doi: 10.1034/j.1600-048x.2000.310 212.x

Nakano, S., and Murakami, M. (2001). Reciprocal subsidies: dynamic interdependence between terrestrial and aquatic food webs. Proc. Natl. Acad. Sci. U.S.A. 98, 166-170. doi: 10.1073/pnas.98.1.166

Nakano, S., Miyasaka, H., and Kuhara, N. (1999). Terrestrial-aquatic linkages: riparian arthropod inputs alter trophic cascades in a stream food web. Ecology 80, 2435-2441. doi: 10.2307/176923

Nie, Y., Zhang, Z., Raubenheimer, D., Elser, J. J., Wei, W., and Wei, F. (2015). Obligate herbivory in an ancestrally carnivorous lineage: the giant panda and bamboo from the perspective of nutritional geometry. Funct. Ecol. 29, 26-34. doi: 10.1111/1365-2435.12302

Nilsson, J. Å, and Källander, H. (2006). Leafing phenology and timing of egg laying in great tits Parus major and blue tits P. caeruleus. J. Avian Biol. 37, 357-363. doi: $10.1111 / \mathrm{j} .2006 .0908-8857.03604 . \mathrm{x}$

Paetzold, A., Schubert, C., and Tockner, K. (2005). Aquatic terrestrial linkages along a braided-river: riparian arthropods feeding on aquatic insects. Ecosystems 8, 748-759. doi: 10.1007/s10021-005-0004-y

Polis, G. A., Anderson, W. B., and Holt, R. D. (1997). Toward an integration of landscape and food web ecology: the dynamics of spatially subsidized food webs. Annu. Rev. Ecol. Syst. 28, 289-316. doi: 10.1146/annurev.ecolsys.28. 1.289

Riddington, R., and Gosler, A. G. (1995). Differences in reproductive success and parental qualities between habitats in the great tit Parus major. Ibis 137, 371-378. doi: 10.1111/j.1474-919x.1995.tb08035.x

Royama, T. (1970). Factors governing the hunting behaviour and selection of food by the great tit (Parus major L.). J. Anim. Ecol. 39, 619-668. doi: 10.2307/2858

Rytkönen, S., Vesterinen, E. J., Westerduin, C., Leviäkangas, T., Vatka, E., Mutanen, M., et al. (2019). From feces to data: a metabarcoding method for analyzing consumed and available prey in a bird-insect food web. Ecol. Evol. 9, 631-639. doi: $10.1002 /$ ece 3.4787

Schilke, P. R., Bartrons, M., Gorzo, J. M., Vander Zanden, M. J., Gratton, C., Howe, R. W., et al. (2020). Modeling a cross-ecosystem subsidy: forest songbird response to emergent aquatic insects. Landsc. Ecol. 35, 1587-1604. doi: 10.1007/ s10980-020-01038-0

Schindler, D. E., Scheuerell, M. D., Moore, J. W., Gende, S. M., Francis, T. B., and Palen, W. J. (2003). Pacific salmon and the ecology of coastal ecosystems. Front. Ecol. Environ. 1:31-37. doi: 10.1890/1540-92952003001[0031:PSATEO]2. $0 . \mathrm{CO} ; 2$

Shutt, J. D., Nicholls, J. A., Trivedi, U. H., Burgess, M. D., Stone, G. N., Hadfield, J. D., et al. (2020). Gradients in richness and turnover of a forest passerine's diet prior to breeding: a mixed model approach applied to faecal metabarcoding data. Mol. Ecol. 29, 1199-1213. doi: 10.1111/mec.15394
Simmonds, E. G., Cole, E. F., Sheldon, B. C., and Coulson, T. (2020). Phenological asynchrony: a ticking time-bomb for seemingly stable populations? Ecol. Lett. 23, 1766-1775. doi: 10.1111/ele.13603

Stenroth, K., Polvi, L. E., Fältström, E., and Jonsson, M. (2015). Land-use effects on terrestrial consumers through changed size structure of aquatic insects. Freshw. Biol. 60, 136-149. doi: 10.1111/fwb.12476

Stock, B. C., Jackson, A. L., Ward, E. J., Parnell, A. C., Phillips, D. L., and Semmens, B. X. (2018). Analyzing mixing systems using a new generation of Bayesian tracer mixing models. PeerJ 6:e5096. doi: 10.7717/peerj.5096

Twining, C. W., Bernhardt, J., Derry, A., Hudson, C., Ishikawa, A., Kabeya, N., et al. (2021). The evolutionary ecology of fatty acid variation: implications for consumer adaptation and diversification. Ecol. Lett. 24, 1709-1731. doi: 10.1111/ele.13771

Twining, C. W., Brenna, J. T., Hairston, N. G., and Flecker, A. S. (2016a). Highly unsaturated fatty acids in nature: what we know and what we need to learn. Oikos 125, 749-760. doi: 10.1111/oik.02910

Twining, C. W., Brenna, J. T., Lawrence, P., Shipley, J. R., Tollefson, T. N., and Winkler, D. W. (2016b). Omega-3 long-chain polyunsaturated fatty acids support aerial insectivore performance more than food quantity. Proc. Natl. Acad. Sci. U.S.A. 113, 10920-10925. doi: 10.1073/pnas.1603998113

Twining, C. W., Brenna, J. T., Lawrence, P., Winkler, D. W., Flecker, A. S., and Hairston, N. G. Jr. (2019). Aquatic and terrestrial resources are not nutritionally reciprocal for consumers. Funct. Ecol. 33, 2042-2052. doi: 10.1111/1365-2435. 13401

Twining, C. W., Lawrence, P., Winkler, D. W., Flecker, A. S., and Brenna, J. T. (2018a). Conversion efficiency of $\alpha$-linolenic acid to omega-3 highly unsaturated fatty acids in aerial insectivore chicks. J. Exp. Biol. 221(Pt 3):jeb165373.

Twining, C. W., Shipley, J. R., and Winkler, D. W. (2018b). Aquatic insects rich in omega-3 fatty acids drive breeding success in a widespread bird. Ecol. Lett. 21, 1812-1820. doi: 10.1111/ele.13156

Twining, C. W., Taipale, S. J., Ruess, L., Bec, A., Martin-Creuzburg, D., and Kainz, M. J. (2020). Stable isotopes of fatty acids: current and future perspectives for advancing trophic ecology. Philos. Trans. R. Soc. B 375:20190641. doi: 10.1098/ rstb.2019.0641

Visser, M., Holleman, L., and Gienapp, P. (2006). Shifts in caterpillar biomass phenology due to climate change and its impact on the breeding biology of an insectivorous bird. Oecologia 147, 164-172. doi: 10.1007/s00442-005-0299-6

Wickham, H. (2011). ggplot2. Wiley Interdiscip. Rev. 3, 180-185. doi: 10.1002/wics. 147

Wilkin, T. A., King, L. E., and Sheldon, B. C. (2009). Habitat quality, nestling diet, and provisioning behaviour in great tits Parus major. J. Avian Biol. 40, 135-145. doi: 10.1111/j.1600-048x.2009.04362.x

Yuen, E. Y., and Dudgeon, D. (2016). Dietary dependence of predatory arthropods on volant aquatic insects in tropical stream riparia. Biotropica 48, 218-228. doi: $10.1111 /$ btp. 12271

Conflict of Interest: The authors declare that the research was conducted in the absence of any commercial or financial relationships that could be construed as a potential conflict of interest.

Publisher's Note: All claims expressed in this article are solely those of the authors and do not necessarily represent those of their affiliated organizations, or those of the publisher, the editors and the reviewers. Any product that may be evaluated in this article, or claim that may be made by its manufacturer, is not guaranteed or endorsed by the publisher.

Copyright (C) 2021 Twining, Parmar, Mathieu-Resuge, Kainz, Shipley and MartinCreuzburg. This is an open-access article distributed under the terms of the Creative Commons Attribution License (CC BY). The use, distribution or reproduction in other forums is permitted, provided the original author(s) and the copyright owner(s) are credited and that the original publication in this journal is cited, in accordance with accepted academic practice. No use, distribution or reproduction is permitted which does not comply with these terms. 